\title{
Transient stability enhancement in the presence of optimally placed D-FACTS
}

\author{
Omar Kamil Dahham Alazzawi, Mustafa Ahmed Nayyef, Yasir Abdulhafedh Ahmed \\ Department of Electrical Engineering, University of Anbar, Iraq
}

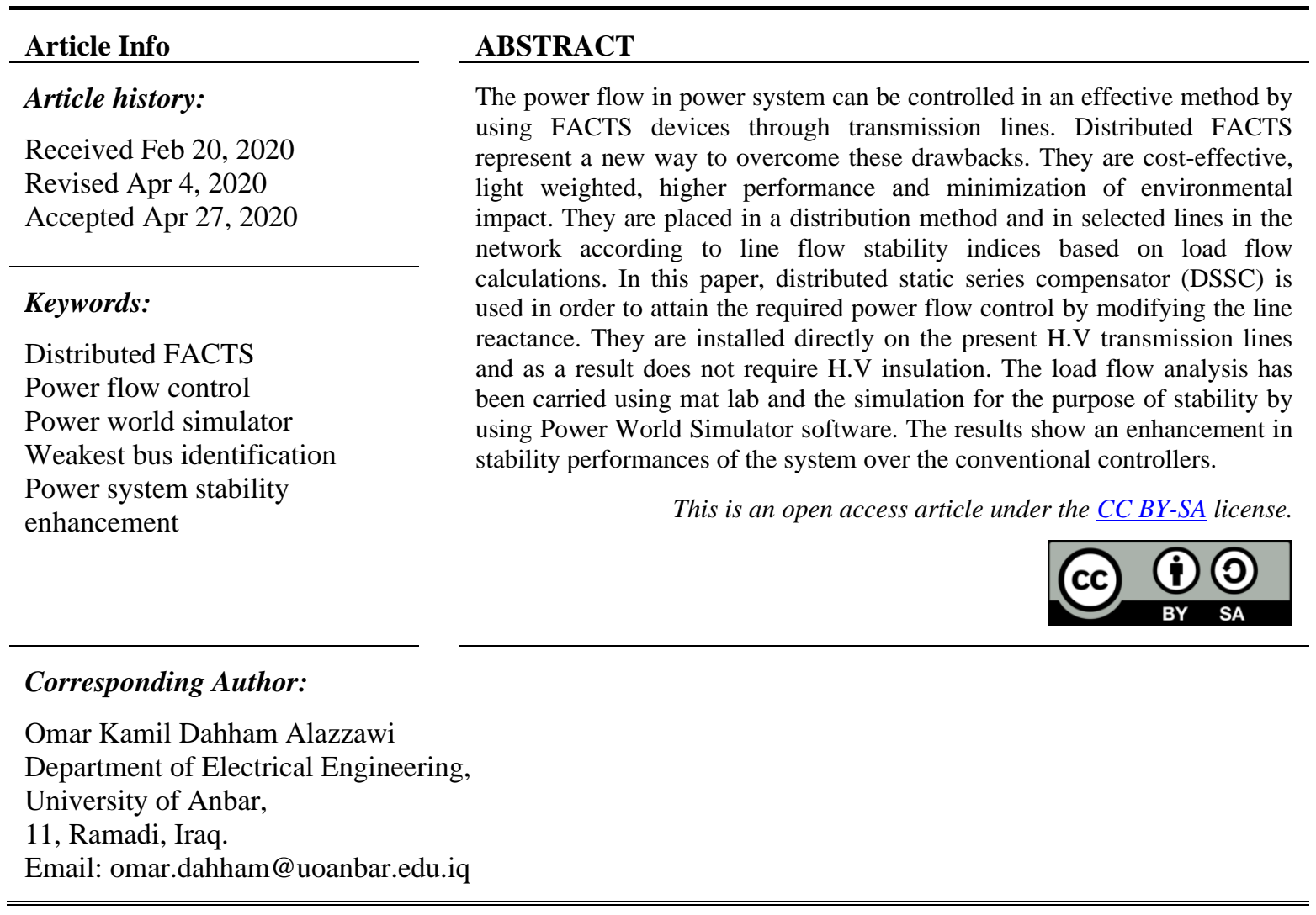

\section{INTRODUCTION}

In modern power system, the process of generation and distribution of electrical energy is complex . It produces new and difficult challenges to the study of stability in order to ensure a stable and reliable operation of power system in the event of sudden faults and disturbances. FACTS controllers offer settlements to these problems which are competent of prevailing the system parameters in order to enhance voltage, steady state and transient stability of the network [1]. Hence it is necessary to produce methods for the purpose of optimal location of FACTS devices satisfying certain constraints. As a result, conventional FACTS have various benefits and D-FACTS have extra benefits and will be explained. D-FACTS represent an alternative device based on efficient cost reduction solution to the load flow problem [2]. The impacts of some of these devices on the stability of a wind farm, especially D-STATCOM, SVC, and Fuzzy SVC controller are presented in [3]. A study of enhancement of power quality by using D-FACTS in distributed networks is proposed in [4]. The goal of paper is to address the issue of stability and quality of power at the degree of combination of wind turbine and diesel generator systems built in D-FACTS systems such a DVR for sustainable electrical power generation. The importance of FACTS for the purpose of compensation of reactive power in the deregulated power system is presented in [5]. It is necessary to compensate for reactive power, boost the actual active power flows in the electrical transmission line, enhance the efficiency of transmission, enhance stability of system and be in an entire position to economize the fossil fuels for aftertime. A study of an optimal location method based on utilization of the sensitivity of total power loss with respect to control parameters of devices is presented in [6]. A methodology for optimal location based 
on the use of an efficient (PI) sensitivity is proposed in [7]. An algorithm proposed for optimal placement of FACTS devices to get the desired voltage stability with optimal sizing of FACTS devices is presented in [8]. A study of the optimal location of FACTS devices using non - dominated sorting particle swarm optimization in Fuzzy framework is proposed in [9]. Firefly optimization algorithm for optimization the rating of UPFC is presented in [10]. The optimal location based on (L-index) and the proposed algorithm is compared with Genetic Algorithm The problem of congestion which means (the transmission system will operate beyond transfer limits) is studied in [11]. D-FACTS are the developed FACTS technology which are distributed through the transmission line as a small device between the small span of transmission line as shown in Figure 1. They can offer series capacitive or inductive reactance in line though SST (single turn transformer). Advantages of D-FACTS over FACTS devices are [12]:

1- It does not require break in line. 2- Small modules (10 Kva and 50-60 kg per module).

3- Compatible and easily upgradable. 4- Bypasses the current so no chances to get damaged.

5- Conventional transmission lines can be used. 6- Distributed over the whole line.

7- No effect of single point failure. 8- Does not require maintenance, if required not costly.

The idea of Distributed Static Synchronous Series Compensator (DSSC) is to employ a low-power single phase inverter, which attaches to the transmission conductor and effectively controls the corresponding transfer impedance and the active control of power flow on the line is achieved as shown in Figure 2 [13].

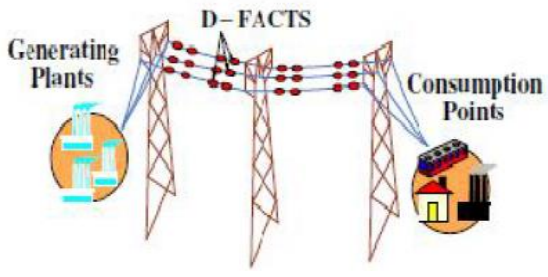

Figure 1. D-FACTS diffuse in transmission line

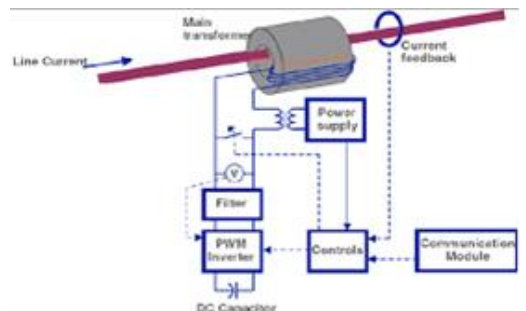

Figure 2. Schematic diagram of DSSC module

\section{PRINCIPLE OF OPERATION OF DSSC}

\subsection{Active power flow concepts}

The series elements have the highest prospect for power flow controlling on transmission lines. Magnitudes of $V_{1}$ and $V_{2}$ govern reactive and active power flow in the line in addition to phase angle difference, $\delta[14]$ :

$$
\begin{aligned}
& P_{12}=\frac{V_{1} * V_{2} * \sin \delta}{X_{l}} \\
& Q_{12}=\frac{V^{2}-V_{1} * V_{2} * \cos \delta}{X_{l}}
\end{aligned}
$$

Where $X_{l}$ represents the line impedance. So, the change of this impedance can be implemented by a series injection of passive inductive or capacitive device in the line. The redundancy gives for continuous operation when a failure occurs in the unit provides high reliability and SST allows treating high values of fault current.

\subsection{D-FACT object and operational profile} and 4 [15]:

The active impedance injunction is produced by synchronous voltage source as shown in Figures 3

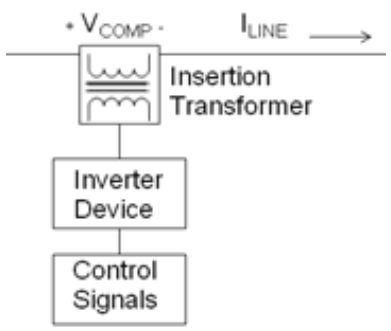


Figure 3. The synchronous voltage source (SVS)

It has the following functions:

a. Injects an A.C voltage, $V_{\text {comp }}$. b. Controls $V_{\text {comp }}$ with respect to $I_{\text {Line }}$ c. Changes effective line Impedance. The given plot explain its function.

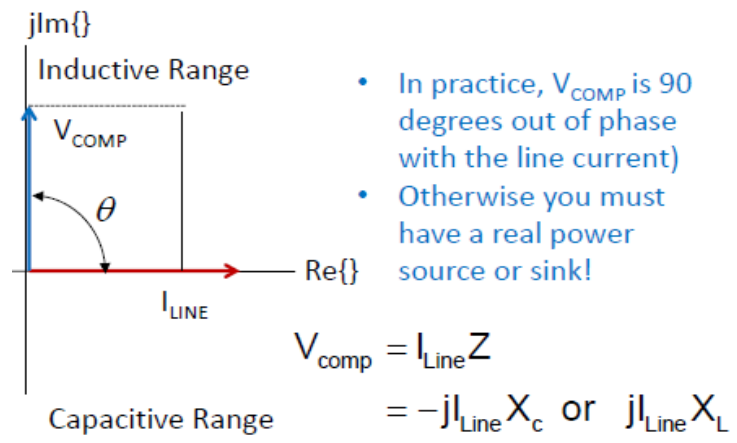

Figure 4. Synchronous voltage source phasor diagram

A single topic symbolizes all the D-FACTS devices on a line are:

- Connects to a transmission line.

- All values are per phase.

- Normally, $47 \mu \mathrm{H}$ per module.

- assign maximum number of modules.

- $\quad$ e. Appoint maximum and minimum line activation current.

Figure 5 shows the D-FACT operational profile. Below $I_{0}$, the D-FACTS devices are inactive and above $I_{\text {lim }}$ the progressive injection of the D-FACTS devices is at its maximum value.

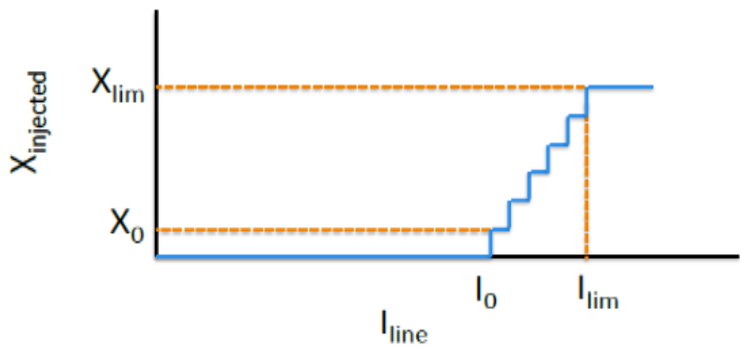

Figure 5. D-FACT operation profile

The D-FACT module consists of a single-phase inverter with small rated (10 KVa) and the weight of the module in the range of (50-60) $\mathrm{kg}$ per module. If the current in the line is greater than the predetermined value, increasing the numbers of modules to be switched and as a result increase the line impedance. Our target is to avoid the lines from thermal over load. The control algorithm of device operation is defined:

$$
L_{\text {inj }}=L_{f} \frac{I-I_{0}}{I_{\text {thermal }}-I_{0}},
$$

$L_{i n j}$ : Line inductance injected, $L_{f}:$ Definitive value of inductance with all modules on the line active. $I_{0}$ : triggering value of current of the module, $I_{\text {thermal }}$ : Thermal limit beyond which there is no injection. An exponentially decaying estimator is needed to minimize interactions between lines and modules: 


$$
L_{\text {exp }}=\left(L_{\text {inj- }} L_{\text {prev }}\right)\left(1-e^{-\left(t-t_{0}\right)}\right)+L_{\text {prev }}
$$

Where $L_{\text {exp }}$ equals actual injunction request at every sampling moment.

\subsection{Simulation of power system using power world simulator}

Power world simulator is a commercial -grade power system analysis and simulation package. It is designed to simulate electrical power systems operating on a time from several minutes to several days [16]. It has the given advantages: [17]

- Flexible and easy for users to interact with all applications in the screen.

- It is a user- friendly Graphical User Interface (GUI) as it includes small source and executable files.

- Allows dynamic interaction with the animated power flow.

- Provide selection of four modes of operation of D-FACT.

\section{METHOD OF WEAKEST LOAD BUS IDENTIFICATION}

Different techniques are presented in papers for weakest bus identification [18]. In this paper, weakest bus identification technique implemented is modified $\left(\frac{d S}{d Y}\right)$ factor using least mean square method (LMPI).

\subsection{Identification of weakest bus using modified ( $\frac{d S}{d Y}$ ) factor (LMPI)}

Consider the given simplified system which consists of a load bus with thevenin circuit to represent the rest of system as simple radial feed to load which serves a certain big network using single transmission line. Simplified thevenin equivalent circuit of local bus as shown in Figure 6.

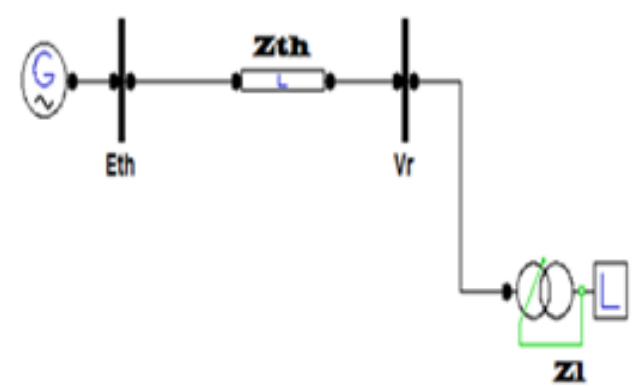

Figure 6. Simplified thevenin equivalent circuit of local bus

The value of current is [19]:

$$
\begin{aligned}
& \mathrm{I}=\frac{E t h}{\sqrt[2]{(Z t h * \cos \theta+Z l * \cos \emptyset)^{2}+(Z t h * \sin \theta+Z l * \sin \emptyset)^{2}}} \\
& \mathrm{I}=\frac{E t h}{\sqrt[2]{Z t h^{2}+Z l^{2}+2 Z t h Z l \cos (\theta-\emptyset)}}
\end{aligned}
$$

where:

$Z_{t h}=\left|Z_{t h}\right|\left\llcorner\theta, Z_{l}=\left|Z_{l}\right|\llcorner\varnothing\right.$, The receiving end voltage of the system is given by

$$
V_{r}=Z_{l} \mathrm{I}=\frac{E \operatorname{th} Z_{l}}{\sqrt[2]{Z t^{2}+Z l^{2}+2 Z \operatorname{th} Z l \cos (\theta-\varnothing)}}
$$

The total apparent power provided in the load is

$$
\mathrm{S}=\frac{V_{r}{ }^{2}}{Z_{l}}=\frac{E t h^{2} Z_{l}}{Z t h^{2}+Z l^{2}+2 Z \operatorname{th} Z l \cos (\theta-\emptyset)}
$$


A plot is drawn between the apparent power $\mathrm{S}$ and load admittance $\mathrm{n}$ as shown in Figure 7. Assuming $E t h=1$ p.u nd $Z t h=1$ p.u for three different values of item $(\theta-\emptyset)=70^{\circ}, 100^{\circ}$ and $120^{\circ}$.

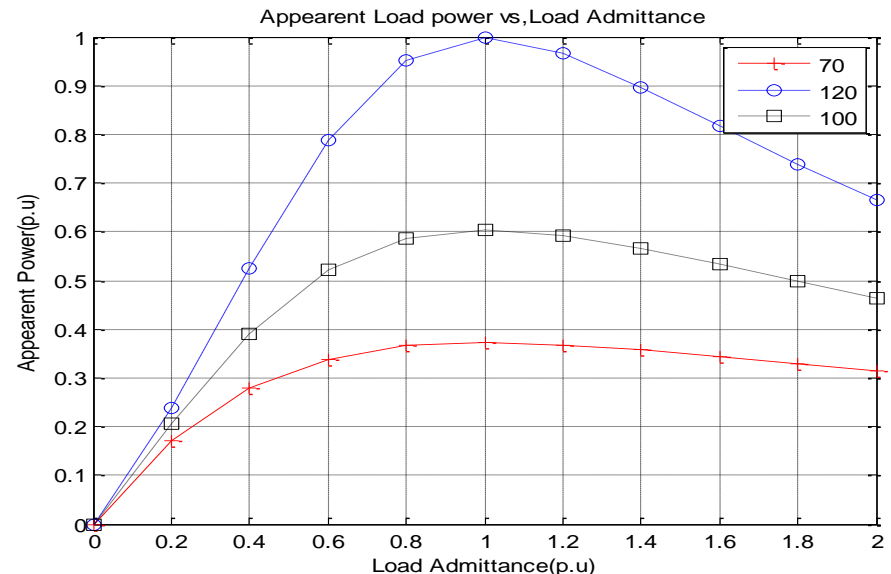

Figure 7. The Load Apparent Power vs. Load Admittance

It is clear from Figure 7 that the increase in load leads to an incremental value of load admittance until reaching maximum, for higher load demand, the action is different and unstable load variation is present [20]. We have

$$
\left(\frac{d S}{d Y}\right)=\frac{E t h^{2}\left(1-Y^{2} Z t h^{2}\right)}{\left(1+Y^{2} Z t h^{2}+2 Z \operatorname{th} Y \cos (\theta-\varnothing)\right)^{2}}
$$

For maximum load condition, $\left(\frac{d S}{d Y}\right)=0$ leads to the solution for critical voltage instability when

$$
Z_{t h}=Z_{l}
$$

Since $\left(\frac{d S}{d Y}\right)$ equals unity at no load $(\mathrm{Y}=0)$ and equals zero at critical maximum load when $Z$ th $=$ $Z_{l}$, it is more accurate to use it for calculation operating points and identify the operating conditions of the system. Points below the maximum loading represent the favorable operating conditions. Therefore, it can be used for the identification of weakest bus and as a result the optimal location of FACT device. The proposed value is:

$$
\left(\frac{d S}{d Y}\right)=\frac{S_{2-S 1}}{Y_{2-Y_{1}}}
$$

It is necessary to study the capability of extracting a new indicator based on this factor and then determine the best fit to data. It uses the method of Least Squares for error reduction and obtain a best fit which make the results more accurate and it is called Least Mean Square Power Indicator (LMPI). We have a data [21].

$$
\left\{\left(x_{1}, y_{1},\right), \ldots \ldots\left(x_{N}, y_{N},\right)\right\}
$$

Then the error associated to $\mathrm{y}=\mathrm{ax}+\mathrm{b}$ may be defined as:

$$
\mathrm{E}(\mathrm{a}, \mathrm{b})=\sum_{n=1}^{N}\left(y_{n^{-}}\left(\mathrm{a} x_{n}+\mathrm{b}\right)\right)^{2}
$$

As the error depends on two variables ( $a$ and $b$ ) then our target is to calculate the values of ( $a$ and $b$ ) such that to minimize the error. Therefore, it is required that to calculate the values of ( $a$ and $b$ ) such that

$$
\left(\begin{array}{l}
a \\
b
\end{array}\right)=\left(\begin{array}{cc}
\sum_{n=1}^{N} x_{n}^{2} & \sum_{n=1}^{N} x_{n} \\
\sum_{n=1}^{N} x_{n} & \sum_{n=1}^{N} 1
\end{array}\right)-{ }^{1}\left(\begin{array}{c}
\sum_{n=1}^{N} x_{n} y_{n} \\
\sum_{n=1}^{N} y_{n}
\end{array}\right)
$$


The best fit of values of ( $a$ and $b$ ) can be obtained by solving the (14) and complete the solution in order to calculate the LMPI indicator. The bus with minimum LMPI represents the weakest bus of the network.

\subsection{Rotor angular stability}

Rotor angle stability indicate the capability of a power system to stay in synchronous after a disturbance. If the disturbance is near the generator, the generator can collapse of point as it has been accelerated during fault. The values of time for such an instability is one to two seconds and it is in shape of a periodic angular separation due to loss of synchronizing torque. [22]. The given Figure 8 shows the rotor angle response for two states [23].

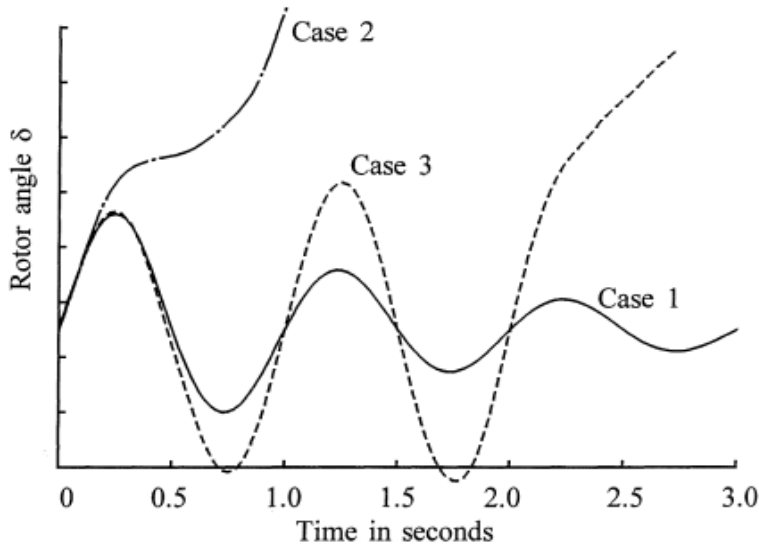

Figure 8. Rotor angle response to a transient disturbance

In power system stability study, the swing equation represents the variation of rotor angle $\delta$ (in electrical radians) with respect to time (in seconds) as indicated

P_a $=P \_m-P \_e=M d 2 \delta / d t^{2}$

The solution provides the data needed for swing curves and when the machine is loaded, rotor angle will be changed and an expression based on swing [24]:

$$
\mathrm{d} \delta / \mathrm{dt}=\left[\frac{P_{a}}{M}\right] \mathrm{t}
$$

\section{RESULTS AND DISCUSSION}

\subsection{Test System (IEEE 9-Bus) with D-FACT}

The IEEE-nine bus test network is shown in Figure 9 and the network data are given in [25]. The network is modelled by using power world simulator with the inclusion and without D-FACT to execute power system stability studies in addition to load-flow program for the purpose of weakest bus identification.

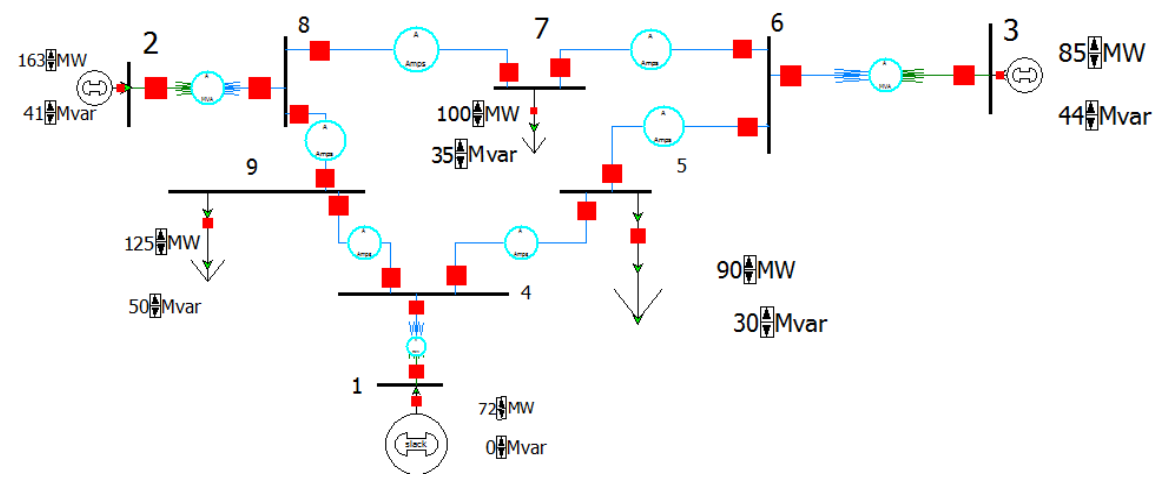


Figure 9. IEEE-Nine bus system

\subsection{Identification of weakest bus using $\left(\frac{d S}{d Y}\right)$}

The calculation is based on loading the three load buses $(5,7,9)$ from normal loading to (1.5) loading in steps of $10 \%$. In each step the factor $\left(\frac{d S}{d Y}\right)$ is calculated according to eq. (11), The results are listed in Table 1.

Table 1. $\left(\frac{d S}{d Y}\right)$ Variation of IEEE 9-Bus with Bus Loading

\begin{tabular}{cccccc}
\hline \multirow{2}{*}{ Bus No. } & \multicolumn{5}{c}{ Load Bus Incremental Loading } \\
\cline { 2 - 6 } 5 & $10 \%$ & $20 \%$ & $30 \%$ & $40 \%$ & $50 \%$ \\
7 & 0.906 & 0.9054 & 0.8634 & 0.8571 & 0.8317 \\
9 & 0.9018 & 0.8858 & 0.8855 & 0.8506 & 0.8294 \\
\hline
\end{tabular}

It is clear from the table given that load bus (9) is the weakest bus in the system. A graph is plotted as shown Figure 10 represents the relation between $\left(\frac{d S}{d Y}\right)$ factor and different load bus loadings.

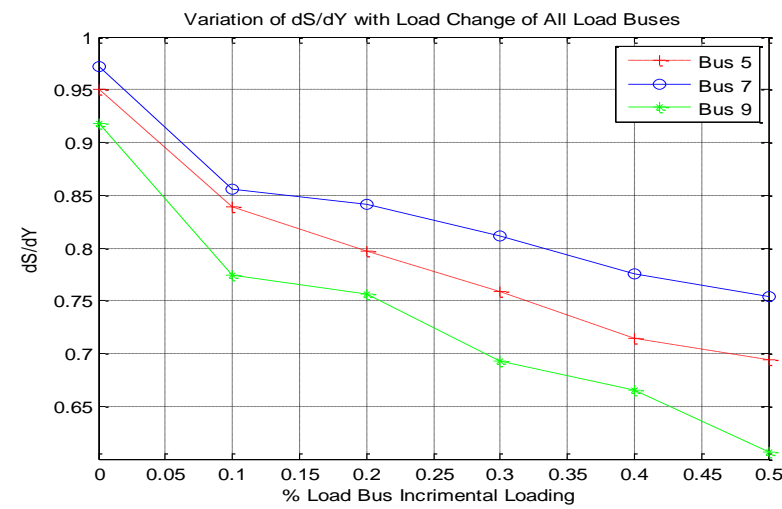

Figure 10. Variation of $\left(\frac{d S}{d Y}\right)$ Factor of IEEE 9-Bus with Bus Loading

\subsection{Identification of weakest bus using modified $\left(\frac{d S}{d Y}\right)$ with LMPI}

The calculation of $\left(\frac{d S}{d Y}\right)$ is enhanced by producing a new indicator for weakest bus identification. The indicator LMPI based using least mean square method for the values of $\left(\frac{d S}{d Y}\right)$ and the lowest values represents the weakest bus as shown in Table 2.

Table 2. LMPI Variation of IEEE 9 with Bus Loading

\begin{tabular}{cccccc}
\hline \multirow{2}{*}{ Bus No. } & \multicolumn{5}{c}{ Load Bus Incremental Loading } \\
& $10 \%$ & $20 \%$ & $30 \%$ & $40 \%$ & $50 \%$ \\
\hline 5 & 0.9121 & 0.8924 & 0.8727 & 0.853 & 0.8333 \\
7 & 0.9066 & 0.8886 & 0.8706 & 0.8525 & 0.8345 \\
9 & 0.8296 & $\mathbf{0 . 8 0 0 7 8}$ & 0.7718 & 0.7429 & 0.714 \\
\hline
\end{tabular}

Figure 11 is plotted which represent the relation of LMPI indicator with different load bus loading which indicates the same result. This means that the use of modified $\left(\frac{d S}{d Y}\right)$ is useful and more accurate and optimal. 


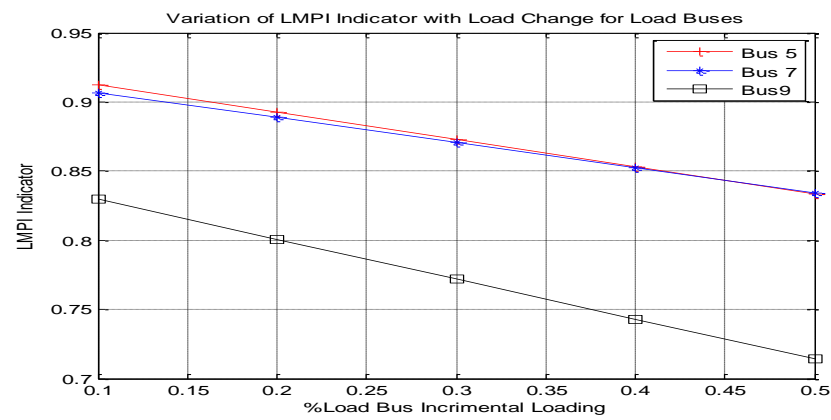

Figure 11. Variation of LMPI of IEEE 9- Bus with Bus Loading

\subsection{IEEE 9-Bus with D-FACT stability study using power world simulator}

The enhancement of power system stability is implemented by insertion of D-FACT in the line connected weakest bus and line (9-4) is selected for D-FACT placement and then studied by using power world simulator program. The process steps are listed below:

a. Load flow implementation using Newton Raphson method using power world simulator.

b. Calculation the design parameters of D-FACT based online flow in line (9-4) and implement in D-FACT module on the line as shown in Figure 12. The line is loaded to its full rating for testing the system to ensure D-FACT is active and select limit based on current operation mode.

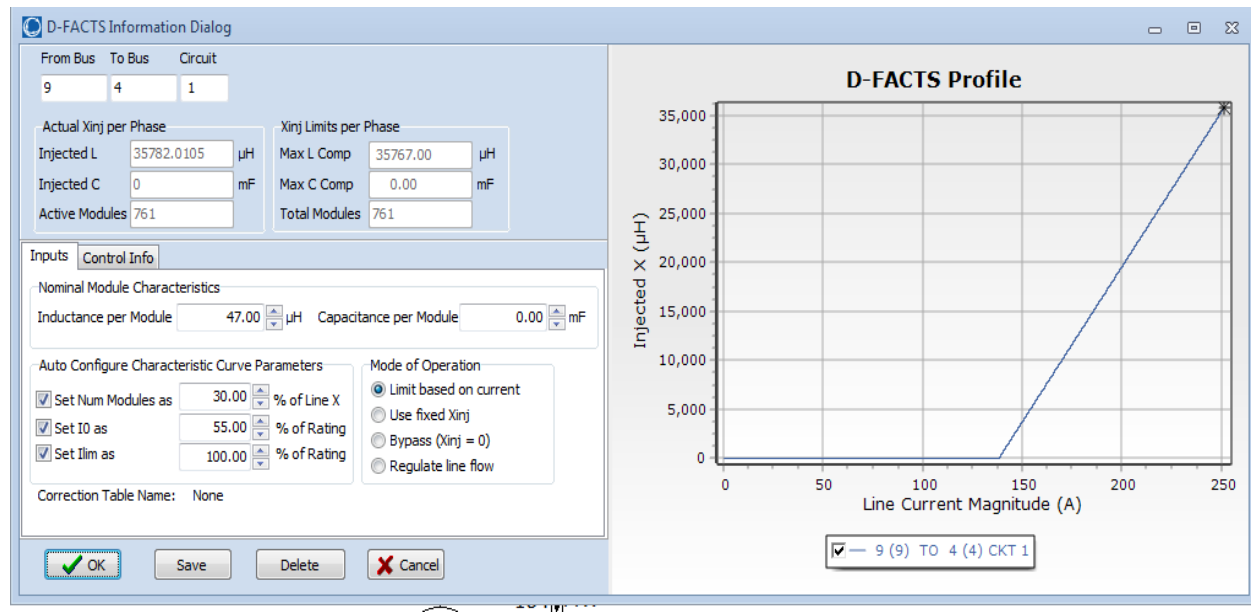

Figure 12. D-FACT design parameters in line (4-9)

Three-phase fault in line (8-9)

a. When the Fault is cleared: A three phase fault is applied in line (8-9) at ( $t_{f}=1 \mathrm{sec}$.) and the fault is cleared and the system is returned to its previous state at $t_{c r}=1.26 \mathrm{sec}$. Figure 13 shows a reduction in rotor angle of Gen. \#2 because of using D-FACT. The same tests are implemented for Gen. \#3 and gives the same conclusion as shown in Figure 14.

b. When the Fault in Line (8-9) is cleared by Opening the Line. Figure 15 shows Gen. \#2 rotor angle when fault is cleared by opening the line at $\mathrm{t} \_\mathrm{cr}=1.158 \mathrm{sec}$. While Figure 16 shows Gen. \#3 rotor angle when fault is cleared by opening the line at $\mathrm{t} \_\mathrm{cr}=1.158 \mathrm{sec}$.

c. Three phase Fault in Bus (8). Another type of fault is studied which is the fault in bus (8). The fault is cleared by reconnection of the breakers of bus (8) to the network with $t_{c r}=1.26 \mathrm{sec}$. Figure 17 shows a reduction in rotor angle of Gen. \#2 because of using D-FACT. Figure 18 shows the same test for Gen. \#3. 
Gen.2 Rotor Angle when 3-Phase Fault at Line(8-9),tcr=1.26 sec.

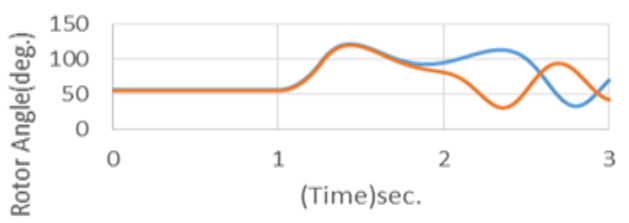

Gen 2 Rotor Angle without D-FACT

Gen 2 Rotor Angle with D-FACT

Figure 13. Gen. 2 rotor angle when 3-phase fault

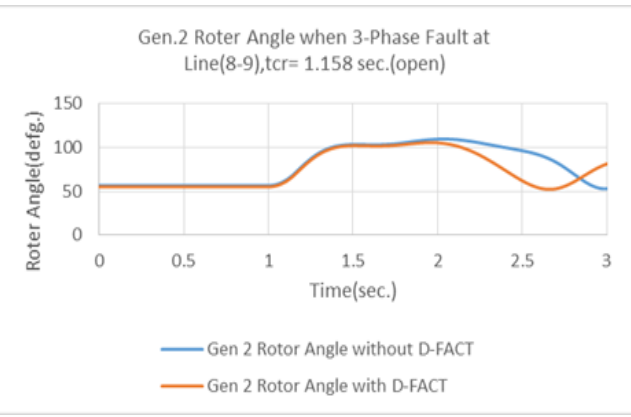

Figure 15. Gen.2 rotor angle when 3-phase

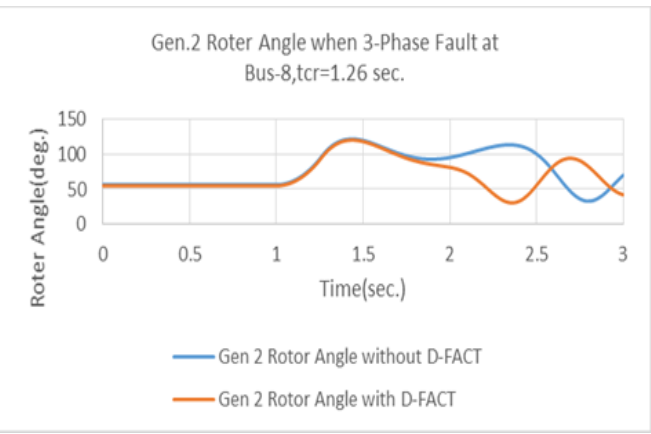

Figure 17. Gen. 2 rotor angle when 3-phase

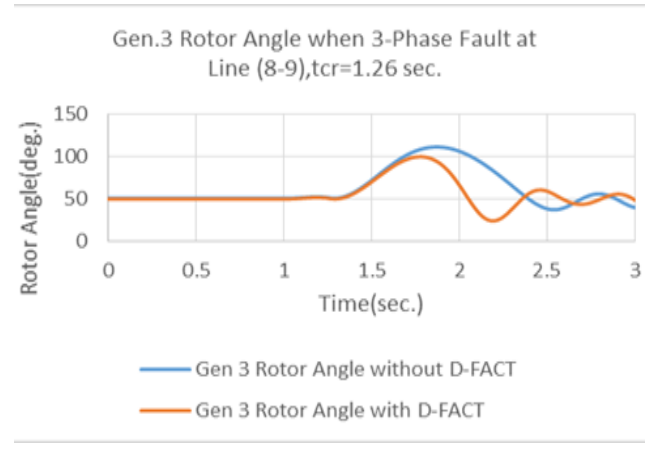

Figure 14. Gen. 3 rotor angle when 3-phase fault

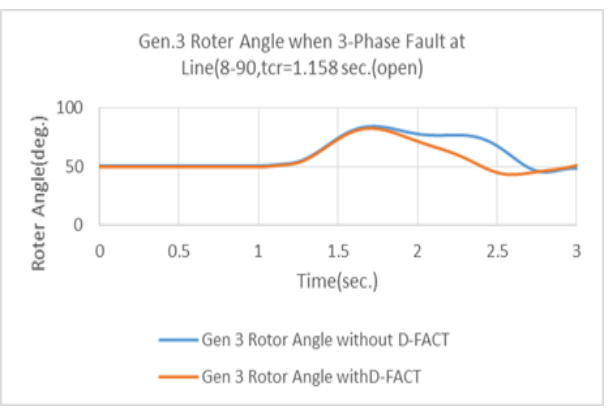

Figure 16. Gen.3 rotor angle when 3-phase fault

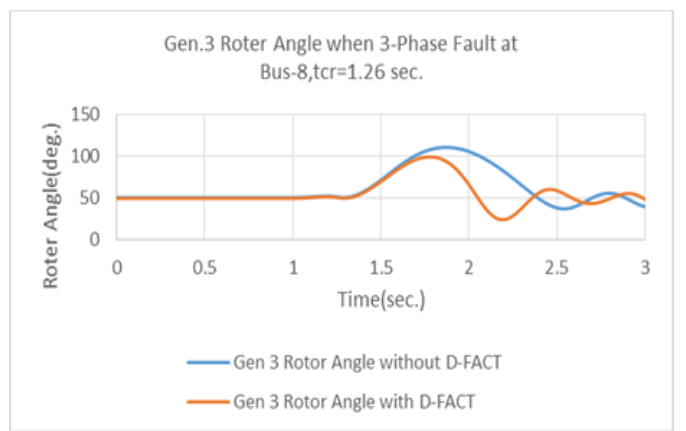

Figure 18. Gen. 3 rotor angle when 3-phase fault at bus 8 fault at bus 8

\section{CONCLUSIONS}

The optimal location and design settings of D-FACTS for transient stability is discussed. The design values of D-FACT are implemented using power world simulator software and different faults were applied in different places in the network. The results show an enhancement in rotor angle and power flow in the network. The slack bus in the network is Gen. \#1 and was not considered because it does not affect by the changes in the network due to its high capacity, which make it slack. The time duration was decreased to 3 seconds as it is important in such type of drawings with high values of rotor angles $\delta$ 。 to be shown in the drawings.

\section{REFERENCES}

[1] Singhal, P., Agarwal, S. K., \& Kumar, N.,"Optimzation of UPFC Controller Parameters Using Bacterial Foraging Technique for Enhancing Power System Stability," International Journal of Advancements in Technology, vol. 5, no. 2, 2014. 
[2] Dhaked, D. K., \& Lalwani, M., "A Review Paper on a D-FACTS Controller Enhanced Power Flow Controller", International Journal of Advances in Engineering \&Technology, vol. 10, no. 1, pp 84-92, 2017.

[3] Rabyi, K., \& Mahmoudi, H.,"Analysis and Impact of D-STATCOM, Static Var Compensator, Fuzzy Based SVC Controller on the Stability of a Wind Farm", International Journal of Power Electronics and Drive Systems (IJPEDS), vol. 8, no. 2, pp.935-944, 2017.

[4] S.A.Zegnoun ,M.N.Tandjaoui, M.Djebbar, C.Benachaiba,and B.Mazari, "Power quality enhancement by using DFACTS systems applied to distributed generation," International Journal of Power Electronics and Drive Systems(IJPEDS), vol. 10, no.1, pp 330-341, 2019.

[5] Packiasudha, M., \& Suja, S., "FACT Device for Reactive Power Compensation in the Deregulated Electrical Power Environment," International Journal of Power Electronics and Drive Systems (IJPEDS), vol. 6, no. 4, pp 730-735, 2015.

[6] Kuthadi, K. K., Babu, M. S., \& Tella, N., "Optimal Location and Parameter Settings of FACTS Devices for Enhancing Power System Stability and Minimization of Power Losses," International Journal of Engineering Science and Technology, vol. 4, no. 6, pp. 2699-2707, 2012.

[7] Parkash, Burade, Jagdish and Helford, "Optimal Location of FACTS Device on Enhancing System Security," International Journal of Scientific \&Engineering Research, vol. 3, no. 5, pp 1-7, 2012.

[8] A. Siva Sankar, K. S. R Anjaneyulu, "Maintaining Voltage Stability by Optimal Locating and Sizing by Combined Evolutionary Algorithm," International Journal of Computer Applications, vol. 84, no. 12, pp. 39-45, 2013.

[9] M. Sedighizadeh, H. Faramarzi and S. Faramarzi, "Optimal Location and Setting of FACTS devices Using NonDominated Sorting Particle Swarm Optimization in Fuzzy Framework," International Journal on Technical and Physical Problems of Engineering, vol. 5, no. 15, pp. 95-107, 2013.

[10] P. Ramesh and M. Damadora Reddy, "Loss Reduction through Optimal Placement of Unified Power -Flow Controller Using Firefly Algorithm," International Journal of Advanced Research in Electrical, Electronics and Instrumentation Engineering, vol. 2, no. 10, pp. 4657-4667, 2013.

[11] Rajasekar Thota and Shaik Hameed, "Optimal Location of Unified Power Flow Controller (UPFC) to Control Active Power Flows and Congestion Management in a Transmission Lines by Using Fuzzy Based Techniques," International Journal of Emerging Trends \&Technology in Computer Science, vol. 3, no. 5, pages 77-82, 2014.

[12] S. Noor Mohammad, N. Narasimhulu, K. M. Siva Sankara Reddy"Multimachine Transient Stability Enhancement with Distributed Static Series Compensator (DSSC)," International Journal of Advanced Research in Electrical, Electronics and Instrumentaion Engineering, vol. 3, no. 2, 2014.

[13] Mansour-Khalilian, Maghsoud-Mokhtari, Daryoosh-Nazarpour, and Bahrouz-Tousi, "Transient Stability Enhancement by DSSC with Fuzzy Suplementary Controller," Journal of Electrical Engineering \& Technology, vol. 5, no. 3, pp. 415-422, 2010.

[14] Deepak Divan and Harjeet Johal, "Distributed FACTS-A New Concept for Realizing Grid Power Flow Control," IEEE Transactions on Power Electronics, vol. 22, no. 6, pp. 8-14, 2007.

[15] Mark Laufenberg, "D-FACTS in Power World Simulator," Power World Corporation, 2014.

[16] Gurpreet Kaur, Navneet Singh Bhangu, "Transient Stability Analysis of IEEE 9 Bus System Using Power World Simulator," International Journal of Advanced Research in Electrical Electronics and Instrumentation Engineering, vol. 5, no. 4, 2016.

[17] Thomas Jove bye, "Power World Simulator," University of Illinois at Urbana-Champaign, 2001

[18] Amit Debnath, Champa Nandi, Joseph Rualkima Rante, "Voltage Profile Analysis for IEEE 30 Bus System Incorporating with UPFC," International Journal of Engineering and Advanced Technology, vol. 2, no. 4, 2013.

[19] A. R. Phadke, Manoj Fozdar, K. R. Niazi, "A New Technique for on-Line Monitoring of Voltage Stability Margin Using Local Signals," Fifteenth National Power Systems Conference, IIT Bombay, pp. 488-492, 2008.

[20] D. K. Rai, "Maximum Permissible Loading and Static Voltage Stability Limit of a Power System Using V-I Polynomial," International Journal of Computational Engineering Research, vol. 2, no. 5, 2012.

[21] Steven J. Miller, "The Method of Least Squares," Mathematics Department, Brown University, vol. 114, 2006.

[22] Prabha Kundur, John Paserba, Venkat Ajjarapu, et al., "Definition and Classification of Power System Stability," IEEE Transactions on Power Systems, vol. 19, no. 2, pp. 1387-1401, 2004.

[23] P. Kundur, "Power System Stability and Control," McGraw-Hill, Inc.

[24] P. Venkatesh, B. V. Manikandan, S. Charles Raja, A. Srinivasan, "Electrical Power Systems, Analysis, Security and Deregulation," PHI Learning Private Limited, Second Printing, 2014.

[25] P. M. Anderson and A. A. Fouad, "Power System Control and Stability," 2nd edition. New York: IEEE Press, 2003. 